\title{
A MULTI-OBJECTIVE MODEL FOR AN INTEGRATED OIL AND NATURAL GAS SUPPLY CHAIN UNDER UNCERTAINTY
}

\author{
Ahmed M. Ghaithan ${ }^{1,3, *}$, Ahmed M. Attia ${ }^{2,3}$ and Salih O. DuffuaA ${ }^{2}$
}

\begin{abstract}
The oil and gas networks are overlapped because of the inclusion of associated gas in crude oil. This necessitates the integration and planning of oil and gas supply chain together. In recent years, hydrocarbon market has experienced high fluctuation in demands and prices which leads to considerable economic disruptions. Therefore, planning of oil and gas supply chain, considering market uncertainty is a significant area of research. In this regard, this study develops a multi-objective stochastic optimization model for tactical planning of downstream segment of oil and natural gas supply chain under uncertainty of price and demand of petroleum products. The proposed model was formulated based on a two-stage stochastic programming approach with a finite number of realizations. The proposed model helps to assess various trade-offs among the selected goals and guides decision maker(s) to effectively manage oil and natural gas supply chain. The applicability and the utility of the proposed model has been demonstrated using the case of Saudi Arabia oil and gas supply chain. The model is solved using the improved augmented $\varepsilon$-constraint algorithm. The impact of uncertainty of price and demand of petroleum products on the obtained results was investigated. The Value of Stochastic Solution (VSS) for total cost, total revenue, and service level reached a maximum of $12.6 \%, 0.4 \%$, and $6.2 \%$ of wait-and see solutions, respectively. Therefore, the Value of the Stochastic Solution proved the importance of using stochastic programming approach over deterministic approach. In addition, the obtained results indicate that uncertainty in demand has higher impact on the oil and gas supply chain performance than the price.
\end{abstract}

Mathematics Subject Classification. 90B15, 90C15, 90C29.

Received January 10, 2021. Accepted October 16, 2021.

\section{INTRODUCTION}

Oil and gas supply chain is long network that constitute many entities starting from oil and gas fields and ends with the customers. Along this network, the oil and gas products pass through several stages including

Keywords. Oil and gas supply chain, optimization under uncertainty, tactical decision making, Pareto efficient solution, multiobjective optimization.

1 Department of Construction Engineering and Management, King Fahd University of Petroleum and Minerals, Dhahran, Saudi Arabia.

2 Department of Systems Engineering, King Fahd University of Petroleum and Minerals, Dhahran, Saudi Arabia.

3 Interdisciplinary Research Center of Smart Mobility and Logistics, King Fahd University of Petroleum and Minerals, P.O. Box 5067, Dhahran 31261, Saudi Arabia.

*Corresponding author: ahmedgh@kfupm.edu.sa 
production, processing, refining, and transformation to different by-products in gaseous and liquefied forms. Stewart and Arnold [43] explained the activities performed along the oil and gas supply chain in details. The oil network involves oil fields, oil and gas separation plants, oil processing plants, refinery plants, storage facilities, and customers. On the other hand, the natural gas network comprises gas fields, gas plants, fractionator plants, storage facilities, and customers. The two networks overlap in different entities and products. For instance, crude oil produced from oil fields contains natural gas termed "associated gas". The associated gas along with the non-associated produced from gas fields are both shipped to gas plants for processing. In addition, propane and butane are produced in both gas fractionator and refinery plants $[5,20,36]$. This overlap between the two networks necessitates the integration and planning of oil and gas supply chain together. Therefore, it is crucial to optimize and integrate both oil and gas networks as a single supply chain.

Another challenge facing the oil producers is managing oil and gas industries in the presence of market uncertainty and variations. The uncertainties may include variations in fuel prices, demands, risks, etc. A high variation in price of petroleum products have been observed in the last few years due to variation in supply, political instability and tendency to utilize renewable energy. This uncertainty has tremendous economic impact on producing and consuming countries. For example, in 2015, the oil prices have declined sharply, as a result, petroleum-producing countries faced budget deficit, and then, many projects were faltered or delayed. Moreover, in 2020, oil prices fell below zero dollars for the first time in the history due to the spread of COVID-19 pandemic. Therefore, optimizing operations of oil and gas supply chain taking into consideration uncertainty as well as integration of both networks is crucial. Stochastic programming is one approach that can develop a robust plan taking into account uncertainties. Another challenge is to develop a decision support system that takes into consideration different conflicting goals i.e., economic, sustainability, environment, etc.

The area of integration of oil and gas supply chain has not been tackled, only $[5,20]$ have developed deterministic models for the upstream and downstream segments, respectively. To the authors knowledge the impact of uncertainty of key market conditions; demand and price has not been tackled in the literature especially in multi-objective optimization as can be discussed in the Section 2 and summarized in Table 1.

To tackle the above-mentioned challenges, this study developed a stochastic multi-objective decision-making model that aims to assist decision makers to effectively manage both oil and gas networks considering various trade-offs among different goals. In addition, the model takes into consideration the impact of oil and gas market fluctuations on decisions. This study aims to develop a stochastic model for an integrated downstream oil and gas supply chain based on two-stage stochastic programming. The model is expected to help in deriving tactical decisions for the supply chain and study the impact of uncertainty of demand and price on these decisions. The optimal tactical decisions are medium range decisions that include the determination of optimal productions, processing, distributions and allocation of final products to demand centers.

The applicability of the proposed model has been validated using a real case of Saudi Arabia oil and gas supply chain. The multi-objective stochastic model is solved using the improved augmented $\varepsilon$-constraint algorithm proposed by Mavrotas and Florios [34]. The deterministic equivalence model of the Saudi case is large and has 23846 variables and 16897 constraints. The paper is structured into the following sections: Section 2 presents and classifies the literature review with focus on stochastic models. Section 3 describes the problem under study. Section 4 develops the multi-objective stochastic optimization model. Section 5 describes the case study. The obtained results are discussed in Section 6. Finally, Section 7 concludes the paper.

\section{Literature REVIEW}

Several studies have been conducted on optimization of Hydro-Carbone Supply Chain (HCSC). This section presents the relevant literature on the optimization of HCSC under uncertainty. Escudero et al. [17] formulated a two-stage stochastic programming model for a multi-period supply chain. The model addressed downstream oil supply chain starting from crude oil supply to refineries up to distribution. The model determined refining and distribution-scheduling activities under uncertainties of demand, cost of supply, and refined oil prices. Dempster et al. [15] formulated a two-stage stochastic planning model that is used for transformation and distribution 
activities of oil supply chain. The optimized oil network comprises of crude oil depots and refinery plants. In recent years, researchers have enriched the literature in the HCSC planning and optimization with the purpose of maximization or minimization of a single objective function. Iakovou [22] dealt with long term decisions of maritime transportation to minimize the transportation and risk costs. The problem is formulated as a multiobjective, multi-commodity, multiple origin-destination pairs, and multimodal problem. The output of their model, a network of routes for transporting vessels between different nodes. The model needs to be modified to account for different scenarios in transportation activities (i.e., robust model).

Lababidi et al. [25] developed a stochastic model for petrochemical supply chain considering uncertainties of demand, prices, and costs of supply and production. Li et al. [28] proposed two tactical programming models; two-stage and chance-constraint models to refinery plant planning considering uncertainties in demand and supply. Their model contains two service objectives: confidence level (i.e., probability of satisfying customer demand) and fill rate (i.e., proportion of the demand satisfied from the refinery plant). The model considered optimizing production rate of a single oil product at refinery and flow quantity of oil to final customer. Neiro and Pinto [37] formulated a multi-period and tactical mixed integer non-linear programming model for optimizing production plans in oil refineries. The model studied the uncertainty in price and demand of crude and oil products. The objective function contained a nonlinear operating cost term as a result of the unit operating mode and inlet stream flow rate.

Al-Othman et al. [1] developed an integrated single objective stochastic model for oil supply chain with uncertainties arising from market demands and prices. Three scenarios are considered for demand and prices; above, base, and below average. In the first stage the production quantities are specified for each type of crude oil, while in the second stage the production quantities of refinery and petrochemical products are optimized. MirHassani [35] developed a two-stage stochastic linear programming model under uncertain demand. The model is used for planning of a petroleum supply chain contains refinery plants and depots with the objective to minimize holding and transportation costs. He studied the effect of transportation capacity on demand fulfillment. Khor et al. [23] developed two-stage stochastic model and stochastic robust programming model to optimize production operation of a refinery. The models considered transforming of crude oil at refinery and the flow of the oil to the final customer. The model addressed uncertainty of crude and oil-by products demand, prices, and yields. The variance was adopted as the risk measure.

Ghatee and Hashemi [21] developed a stochastic model considering daily production of each unit in supply chain, daily exportation of each port, refinery intake, pipelines and storage capacities. Carneiro et al. [10] formulated a two-stage scenario based stochastic programming model incorporating conditional value at risk $(\mathrm{CVaR})$ a risk measure to maximize the expected portfolio return. Al-Qahtani and Elkamel [3] extended the deterministic model of Al-Qahtani and Elkamel [2] by incorporating uncertainties of crude oil supply and final products demand and prices. Two models were formulated; the first model is a MILP stochastic model and the second model is a robust mixed integer no-linear programming model. The sample average approximation (SAA) is employed to generate the required samples. They considered crude oil processing at refineries and marketing of refined oil refined products locally and internationally, and imports of refined oil products.

Ribas et al. [41] formulated stochastic and robust models for strategic decision making. The considered uncertain parameters are oil products demands and prices. A comparison was conducted for performance of the two models. The proposed model comprises refinery and petrochemical plants. The inlet crude oil to the refinery plants are from local, international, gas, and vegetable oil. Leiras et al. [26] extended Ribas et al. [40] and Al-Qahtani and Elkamel [2] work by considering material supplies cost and final item price as uncertain parameters. The model investigated the strategic planning decisions related to refineries integration. Yang et al. [45] utilized Markov chain to represent the fluctuation of product yield of refineries. They used chance constraint programming in the formulation. Ribas et al. [41] formulated a stochastic model considering uncertainty in prices and demands. The model used for refineries production planning considering environmental legislation (e.g., limiting the sulfur production).

Tong et al. [44] built a stochastic model with the assumption of demand uncertainty and production fluctuation. The model considered risks from customer resentment and inventory infringement. The model was solved 
using a heuristic algorithm integrated with a simulation framework based on iterative procedure, where, the optimality needs more work to be proved. Oliveira and Hamacher [38] formulated a strategic stochastic programming model for distributing petroleum products under the assumption of uncertain demand. The proposed model did not consider the processing of crude oil and the importation of products. Tong et al. [44] incorporated CVaR in the objective function, and estimated the threshold value by SAA. Oliveira et al. [39] developed a stochastic model used for design and capacity expansion with the assumption of stochastic demand. The considered network compromises of supply nodes, primary and secondary bases. Fernandesa et al. [18] formulated a stochastic model to maximize net present value based on demand uncertainty.

Azadeh et al. [7] presented a multi-objective model for planning natural gas supply chain considering the uncertainty of demand, capacity, and costs as a fuzzy parameter for minimizing the total costs and environmental costs. The model was solved through two steps first by getting the deterministic equivalent, and second by converting the model into a single objective. Within the few research works that considered environmental legislation; Liqiang and Guoxin [32] proposed a model oriented around $\mathrm{CO}_{2}$ emissions. They mitigate the carbon emissions through minimizing the taxes from environment legislation.

Azadeh et al. [8] proposed a deterministic MINLP model to design both segments of crude oil supply chain. The model optimizes development of oil field and crude oil processing and distribution. Lima et al. [31] proposed a multistage stochastic programming model to optimize production, and distribution activities of refined products with the aim of profit maximization. The model considered demand and price as uncertain parameters. Ghaithan et al. [20] optimized oil and gas supply chain in an integrated network under the assumption of certain environment. For further reading, recent reviews conducted by Lima et al. [30] and Sahebi et al. [42] in the area of application of mathematical programming techniques. Also, Leiras et al. [27] reviewed the literature for techniques and methodologies used for optimizing refinery operations. Table 1 summarizes the relevant works in terms of type of supply chain, optimization approach, and considered uncertain parameters.

Despite of the intensive work in the area of hydrocarbon supply chain optimization, several gaps have been observed. For instance, it has been noticed that most researches have optimized oil and gas separately. Moreover, the oil and gas supply chain has not been integrated especially in a multi-objective stochastic framework. Therefore, this paper is an attempt to fill the above-mentioned gaps by developing a multi-period and multiobjective stochastic mathematical model under uncertainty of key market conditions.

\section{Problem statement}

The oil and gas products pass through a long journey before they reach the final customers. Due to the long and complexity of the oil and gas supply, researches divided the network into segments [42] namely, upstream and downstream. The borders between the two segments are subjective. The upstream segment consists of various entities, namely, oil and natural gas fields, gas oil separation plants, and storage facilities. The downstream segment comprises oil processing plants, gas plants, refinery plants, fractionator plants, export terminals, and import terminals as shown in Figure 1. Many activities are performed along the oil and gas supply chain such as transportation, crude oil processing, natural gas separation, crude oil refining, refined products transportation, storage, distribution, and marketing [43].

The final petroleum products goes through many processing and transforming activities to be ready for the final use; as follows: Sour oil produced at oil fields is shipped to oil storages and then distributed to processing plants for sweetening process to remove impurity sulfur. After sweetening, the sour oil is then called crude oil that is used to satisfy international market demand and local demand of refinery plants. The crude oil is further transformed in refinery plants into its oil by-products, namely, diesel, naphtha, gasoline, propane, butane, fuel oil, asphalt, and kerosene. The oil by-products are then stored in bulk plants before distribution to local, export terminals, and industry customers.

There are two types of natural gases; associated and non-associated natural gases. The associated natural gas is separated from crude oil at gas oil separation plants (GOSPs) while the non-associated natural gas is produced directly from pure gas fields. The two gas streams are then shipped to gas storages and then distributed to gas 
TABLE 1. Summary of the relevant works.

\begin{tabular}{|c|c|c|c|c|c|c|c|c|}
\hline \multirow[t]{2}{*}{ Reference } & \multicolumn{2}{|c|}{ Network } & \multicolumn{2}{|c|}{ Optimization approach } & \multicolumn{4}{|c|}{ Uncertain parameter } \\
\hline & Oil & Gas & $\begin{array}{l}\text { Single } \\
\text { objective }\end{array}$ & $\begin{array}{l}\text { Multi- } \\
\text { objective }\end{array}$ & Price & Demand & Yield & Others \\
\hline Escudero et al. [17] & $*$ & & * & & * & * & & \\
\hline Dempster et al. [15] & $*$ & & * & & * & $*$ & & \\
\hline Iakovou $[22]$ & $*$ & & & $*$ & & & & \\
\hline Lababidi et al. [25] & $*$ & & * & & * & $*$ & & $*$ \\
\hline Li et al. $[28]$ & $*$ & & $*$ & & $*$ & $*$ & & \\
\hline Neiro and Pinto [37] & $*$ & & * & & $*$ & $*$ & & \\
\hline Khor et al. [23] & * & & * & & * & * & * & \\
\hline Al-Qahtani et al. [2] & $*$ & & * & & $*$ & $*$ & * & \\
\hline Al-Othman et al. $[1]$ & $*$ & & $*$ & & $*$ & $*$ & & \\
\hline Ghatee and Hashemi [21] & $*$ & & * & & & $*$ & & \\
\hline Yang et al. [45] & * & & * & & & & $*$ & \\
\hline Al-Qahtani and Elkamel [3] & $*$ & & * & & $*$ & * & & \\
\hline Leiras et al. [26] & $*$ & & * & & * & * & & \\
\hline Carneiro et al. [10] & $*$ & & * & & $*$ & * & & \\
\hline Ribas et al. $[40]$ & * & & * & & * & * & & \\
\hline Ribas et al. [41] & * & & * & & $*$ & * & & \\
\hline MirHassani and Noori [35] & $*$ & & $*$ & & & $*$ & & \\
\hline Tong et al. [44] & * & & * & & & * & * & * \\
\hline Oliveira and Hamacher [38] & $*$ & & * & & & * & & \\
\hline Oliveira et al. [39] & * & & * & & & * & & \\
\hline Liqiang and Guoxin [32] & $*$ & & * & & * & & & \\
\hline Fernandesa et al. [18] & * & & * & & & * & & \\
\hline Azadeh et al. [7] & & * & & $*$ & & $*$ & & * \\
\hline Azadeh et al. [8] & * & & * & & & & & \\
\hline Lima et al. [31] & $*$ & & $*$ & & * & $*$ & & \\
\hline This paper & $*$ & * & & * & * & * & & \\
\hline
\end{tabular}

plants to be processed into natural gas liquid (NGL), methane and hydrogen sulfide. The methane is used as raw material by industries and the NGL is fractionated in fractionator plants into its gas by-products including ethane, propane, butane and natural gasoline. The gas by-products are utilized to satisfy local, industry, and international demands [20]. The shortages of oil and gas are fulfilled from international markets represented by the import terminals in Figure 1.

As per the above discussion, there is an overlap between the oil and gas networks due to the existence of natural gas associated with crude oil. Moreover, propane and butane gases are produced in refinery plants as well as fractionation plants. This overlap necessitates the integration and planning of oil and gas supply chain together.

The oil and gas supply chain comprises uncertain parameters such as supply, demand, price, yields, etc. For instance, in the last years, huge variations in petroleum products demand and price has been noticed. Therefore, when modeling oil and gas supply chain, it is important to consider these uncertainties. In addition, decision maker(s) should take into account the trade-off between economic and customer satisfaction objectives. In this study, each uncertain parameter is represented by discrete possible realization/scenarios with a specific probability of occurrence. The model is formulated based on two-stage stochastic programming approach with recourse [14], also known as scenario based analysis [9]. The location of first and second stage decision variables are illustrated in Figure 1. The first-stage decisions include the supply from upstream to the oil and gas 


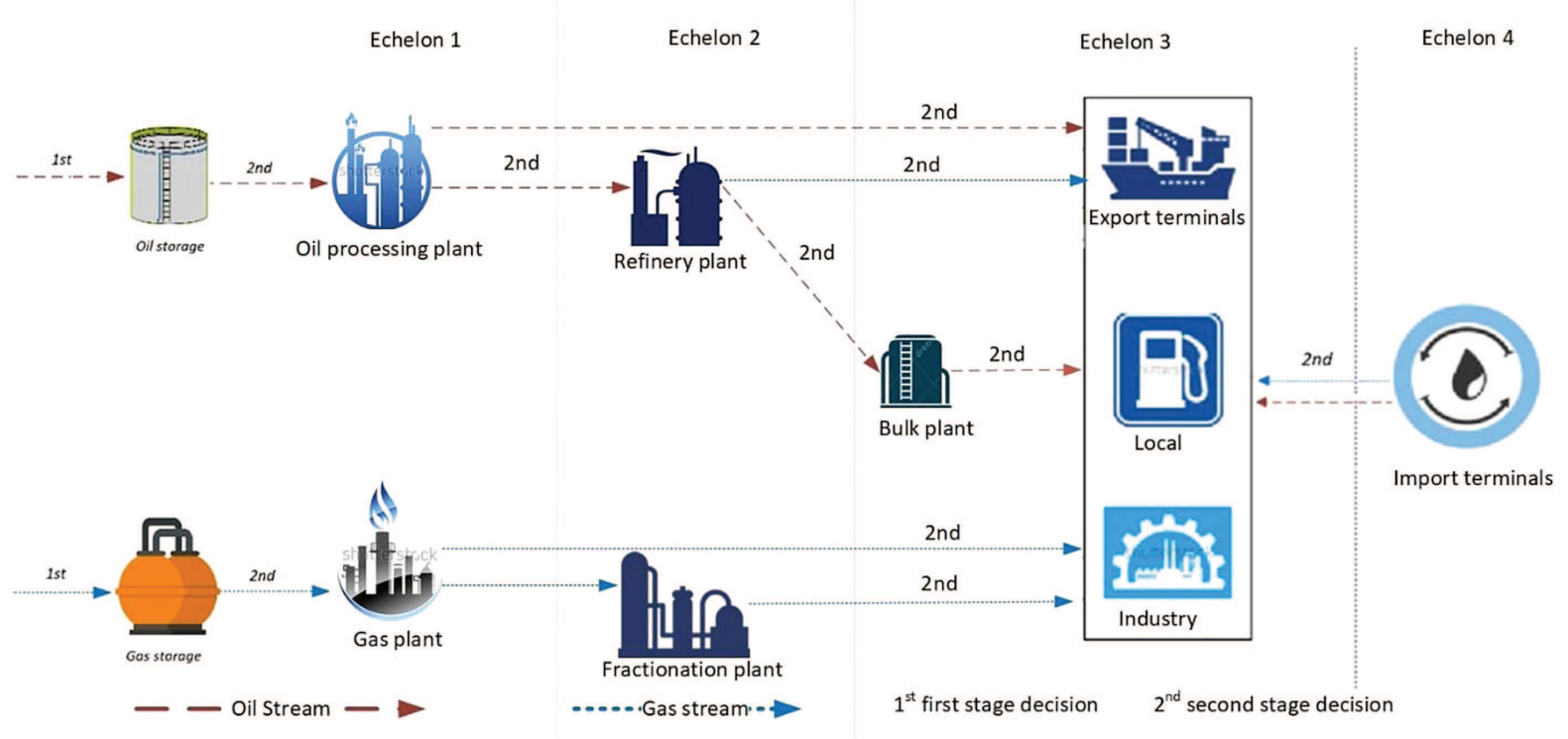

Figure 1. Schematic representation of oil and gas supply chain [20].

storages/inventories. These decisions should be made prior to the realization of demand and price. The secondstage decisions comprise quantities of all shipments between each two nodes in the network, productions, inventory levels, as well as importation and exportation quantities.

The tactical decisions will be optimized while taking into consideration limitations of plants capacities, demand, material balance, and quota specified by Organization of the Petroleum Exporting Countries (OPEC). The proposed multi-objective stochastic model is solved using the augmented $\varepsilon$-constraint algorithm, which is an improved version of the classical $\varepsilon$-constraint method. In the $\varepsilon$-constraint method, the generated Pareto optimal points involve weak efficient solutions. The augmented $\varepsilon$-constraint algorithm generates Pareto optimal solutions without providing weak solutions by setting other objectives as binding constraints. Therefore, the solutions are reached quickly as a result of avoiding the generation of weak solutions. In the following sections the model is developed, solved, and its results are analyzed.

\section{Mathematical model Formulation}

The integrated oil and gas supply chain has been optimized by developing a stochastic model based on two-stage stochastic programming approach. The two-stage stochastic programming formulation is a decisionmaking approach in which decisions are performed sequentially in two stages. The first stage decisions $x$ are made before having clear information about the uncertain parameters $\lambda(\omega)$. After recognition of the uncertain parameter $\lambda$, the second stage decisions $y$ are made. A recourse action is taken during the second stage after the uncertainty is resolved. The stochastic formulation for the two-stage problem in terms of a single objective is shown below, equations (4.1)-(4.6) and its corresponding deterministic equivalent is provided in equations $(4.7)-(4.10),[12]$.

$$
\operatorname{Maximize}_{x} z=c^{T} x+E\{Q(\omega)\}
$$


subject to $A x=b$

$$
x \in X
$$

where

$$
\begin{aligned}
& Q(\omega)=\left\{\text { Maximize }_{y(\omega)} q(\omega)^{T} y(\omega)\right. \\
& \text { subject to } T(\omega) x+W(\omega) y(\omega)=h(\omega) \\
& y(\omega) \in Y\},
\end{aligned}
$$

The deterministic equivalent model of the above formulation is shown below:

$$
\begin{aligned}
\operatorname{Maximize}_{x, y(\omega)} & z=c^{T} x+\sum_{\omega \in \Omega} \pi(\omega) q(\omega)^{T} y(\omega) \\
\text { subject to } & A x=b \\
& T(\omega) x+W(\omega) y(\omega)=h(\omega), \\
& x \in X, y(\omega) \in Y,
\end{aligned}
$$

To prove the importance of considering uncertain price and demand on the model performance, the Expected Value of Perfect Information (EVPI) and the Value of the Stochastic Solution (VSS) are used. The EVPI represents the quantity that decision maker(s) is willing to pay for obtaining perfect information about the future. The EVPI is calculated as the difference between the wait and see solutions $\left(Z^{\mathrm{WS}}\right)$ and the stochastic solutions $\left(Z^{\mathrm{S}}\right)$. The EVPI is represented mathematically for maximization and minimization problems as [12]:

$$
\begin{aligned}
& \mathrm{EVPI}_{\text {max }}=Z^{\mathrm{WS}}-Z^{\mathrm{S}} \\
& \mathrm{EVPI}_{\text {min }}=Z^{\mathrm{S}}-Z^{\mathrm{WS}}
\end{aligned}
$$

where the $Z^{\mathrm{WS}}$ is the mean of objective function obtained by solving the problem separately for each scenario. The VSS is an indicator to the advantage of using a stochastic programming over a deterministic approach. The VSS is the difference between the expected value solution $\left(Z^{\mathrm{EV}}\right)$ and the stochastic solution $\left(Z^{\mathrm{S}}\right)$ which represented mathematically for maximization and minimization problems as [12]:

$$
\begin{aligned}
& \mathrm{VSS}_{\text {max }}=Z^{\mathrm{S}}-Z^{\mathrm{EV}} \\
& \mathrm{VSS}_{\text {min }}=Z^{\mathrm{EV}}-Z^{\mathrm{S}} .
\end{aligned}
$$

The $Z^{\mathrm{EV}}$ is determined as follows: first the mean of each stochastic parameter is determined and the problem is solved as deterministic problem. Then the obtained solutions are considered as first stage decisions for the stochastic problem. The stochastic model is then solved to determine the second-stage decisions. The obtained objective function is the EEV solution. The notations used to develop the proposed model are listed in Table 2.

\subsection{Objective functions}

The objective functions are defined in equations (4.15)-(4.18). The total cost; equation (4.15) involves two main parts; deterministic and stochastic terms. The deterministic term involves holding costs of raw material coming from upstream to the oil and gas storages. The second stage terms contain the expected costs of transforming and separation, transportation, holding, and penalty costs of producing over and under the specified demand.

$$
\operatorname{Min} Z_{1}=\sum_{i \in S} \sum_{r \in R} \sum_{t \in T} H c_{i t}^{r} Y_{i t}^{r}+\sum_{\omega \in \Omega} \pi_{\omega}\left[\sum_{i \in S} \sum_{j \in N 1} \sum_{r \in R} \sum_{t \in T} C p_{i j t}^{r} X_{i j w t}^{r}+\sum_{i \in N 1} \sum_{j \in N} \sum_{p \in P} \sum_{t \in T} C p_{i j t}^{p} X_{i j w t}^{p}\right.
$$


TABLE 2. The notations.

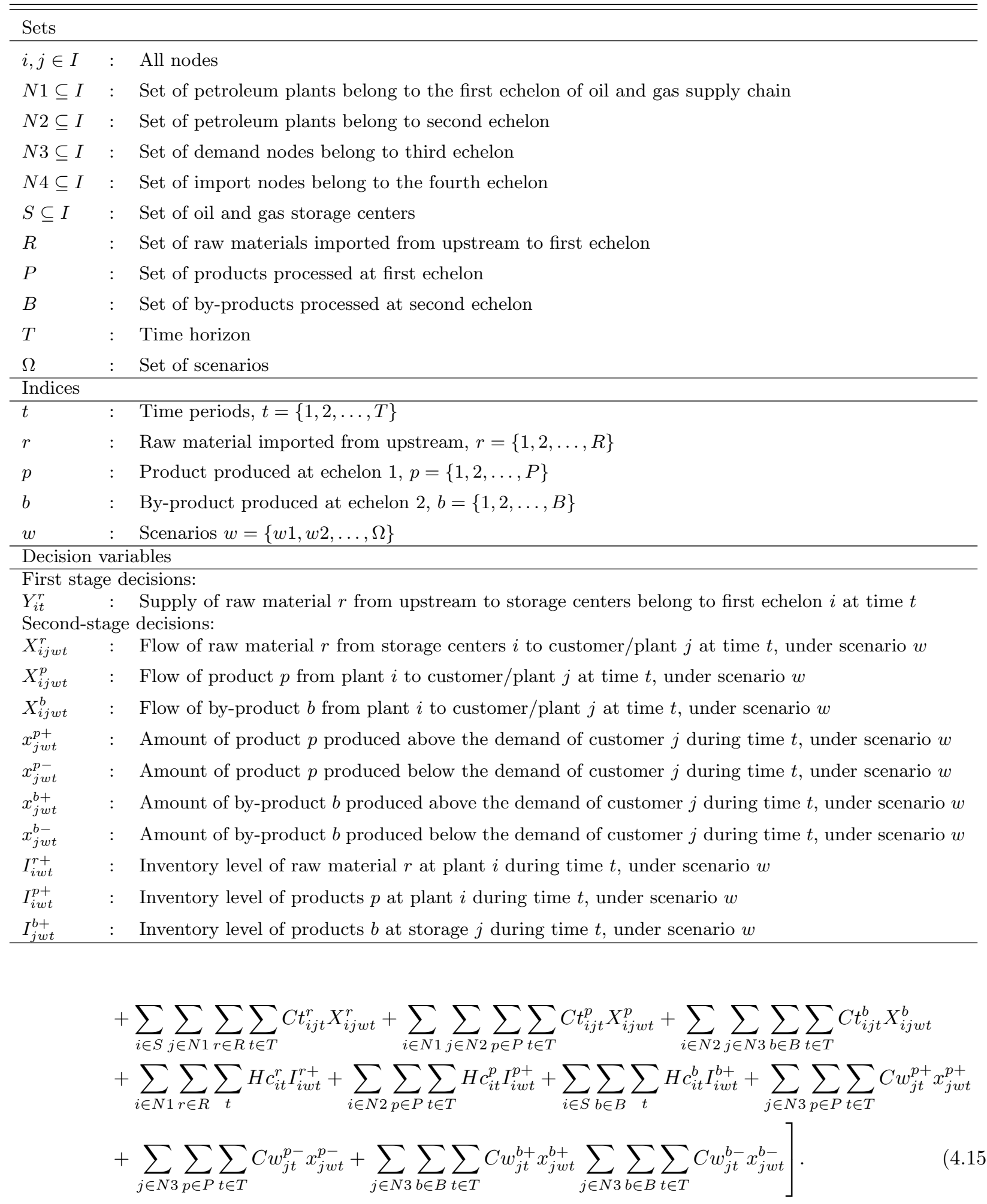


TABLE 2. continued.

\begin{tabular}{|c|c|c|}
\hline \multicolumn{3}{|c|}{ Parameters } \\
\hline$C a_{i}$ & : & Capacity of plant $i$ \\
\hline$C r_{i j}$ & : & Capacity of route connecting plant $i$ with plant/customer $j$ \\
\hline$D_{j w t}^{p}$ & : & Demand quantities of product $p$ at demand node $j$ at time $t$, under scenario $w$ \\
\hline$D_{j w t}^{b}$ & : & Demand quantities of by-product $b$ at demand node $j$ at time $t$, under scenario $w$ \\
\hline$C p_{i j t}^{r}$ & $:$ & $\begin{array}{l}\text { Cost of processing product stream } X_{i j w t}^{r} \text { coming from storage centers } i \text { and processed at plant } j \text { at } \\
\text { time } t\end{array}$ \\
\hline$C p_{i j t}^{p}$ & : & Cost of processing product stream $X_{i j w t}^{p}$ coming from plant $i$ and processed at plant $j$ at time $t$ \\
\hline$C t_{i j t}^{r}$ & : & Cost of shipping raw material $r$ from storage centers $i$ to customer/plant $j$ at time $t$ \\
\hline$C t_{i j t}^{p}$ & : & Cost of shipping product $p$ from plant $i$ to customer/plant $j$ at time $t$ \\
\hline$C t_{i j t}^{b}$ & : & Cost of shipping by-product $b$ from plant $i$ to customer/plant $j$ at time $t$ \\
\hline$C w_{j t}^{p+}$ & : & Cost incurred due to producing product $p$ more than the demand of customer $j$ at time $t$ \\
\hline$C w_{j t}^{p-}$ & : & Cost incurred due to producing product $p$ less than the demand of customer $j$ at time $t$ \\
\hline$C w_{j t}^{b+}$ & : & Cost incurred due to producing by-product $b$ more than the demand of customer $j$ at time $t$ \\
\hline$C w_{j t}^{b-}$ & : & Cost incurred due to producing by-product $b$ less than the demand of customer $j$ at time $t$ \\
\hline$H c_{i t}^{r}$ & : & Inventory holding cost of raw material $r$ per period $t$ at plant $i$ \\
\hline$H c_{i t}^{p}$ & : & Inventory holding cost of product $p$ per period $t$ at plant $i$ \\
\hline$S p_{j w t}^{p}$ & : & Price of product $p$ at demand node $j$ at time $t$, under scenario $w$ \\
\hline$S p_{j w t}^{b}$ & $:$ & Price of by-product $b$ at demand node $j$ at time $t$, under scenario $w$ \\
\hline$w_{i t}^{r}$ & : & $\begin{array}{l}\text { Composition of product } r \text { obtained from raw materials streaming from upstream segments to storage } \\
i \text { at time } t\end{array}$ \\
\hline$w_{i j t}^{p}$ & $:$ & $\begin{array}{l}\text { Composition of product } p \text { obtained from raw materials streaming from storage centers } i \text { to plant } j \\
\text { at time } t\end{array}$ \\
\hline$w_{i j t}^{b}$ & : & Composition of by-product $b$ obtained from product $p$ streaming from plant $i$ to plant $j$ at time $t$ \\
\hline $\mathrm{OPEC}_{t}$ & : & Market share of crude oil specified to an oil petroleum country at time $t$ \\
\hline$\pi_{\omega}$ & : & Probability of scenario $w$ \\
\hline
\end{tabular}

Equation (4.16) represents the expected total revenue after subtracting the over-production quantities.

$$
\begin{aligned}
\operatorname{Max} Z_{2}= & \sum_{\omega \in \Omega} \pi_{\omega}\left[\sum_{i \in N} \sum_{j \in N 3} \sum_{p \in P} \sum_{t \in T} S p_{j w t}^{p} X_{i j w t}^{p}-\sum_{j \in N 3} \sum_{p \in P} \sum_{t \in T} S p_{j w t}^{p} x_{j w t}^{p+}\right. \\
& \left.+\sum_{i \in N 2} \sum_{j \in N 3} \sum_{b \in B} \sum_{t \in T} S p_{j w t}^{b} X_{i j w t}^{b}-\sum_{j \in N 3} \sum_{b \in B} \sum_{t \in T} S p_{j w t}^{b} x_{j w t}^{b+}\right]
\end{aligned}
$$

Equation (4.17) represents the service level objective function.

$\operatorname{Max} Z_{3}=\sum_{\omega \in \Omega} \pi_{\omega} \frac{\sum_{i \in N 1} \sum_{j \in N 3} \sum_{p \in P} \sum_{t \in T}\left[X_{i j w t}^{p}-x_{j w t}^{p+}\right]+\sum_{i \in N 2} \sum_{j \in N 3} \sum_{b \in B} \sum_{t \in T}\left[X_{i j w t}^{b}-x_{j w t}^{b+}\right]}{\sum_{j \in N 3} \sum_{p \in P} \sum_{t \in T} D_{j w t}^{p}+\sum_{j \in N 3} \sum_{b \in B} \sum_{t \in T} D_{j w t}^{b}}$. 


\subsection{Model constraints}

\section{Material balance}

Constraint (4.18) represents the material balance at storage centers. The input to the storage centers plus the inventory remains from the previous period equal to flow from storage centers to the plants of first level plus inventory level at the current period.

$$
w_{i t}^{r} Y_{i t}^{r}+I_{i w t-1}^{r+}=\sum_{j \in N 1} X_{i j \omega t}^{r}+I_{i w t}^{r+} \quad \forall i \in S, r \in R, t \in T, w \in \Omega .
$$

The material balance of the plants belong to the first level are represented by constraint (4.19). The material flow from upstream plus the inventory left from the previous period equal production volumes at each plant. The processed quantities are then shipped to the next echelon to satisfy the local and international demands. The flow quantities between each two entities of the oil and gas supply chain depends on the realization of the uncertain parameters; $\omega$.

$$
\sum_{r} \sum_{i \in S} w_{i j t}^{p} X_{i j w t}^{r}+\sum_{r} I_{j w t-1}^{r+}=\sum_{k \in N 2, N 3} X_{j k w t}^{p}+\sum_{r} I_{j w t}^{r+} \quad \forall p \in P, j \in N 1, k>j, w \in \Omega, t \in T .
$$

The inlet to the second echelon of the oil and gas supply chain is then processed and fractionated to byproducts based on its compositions. The by-products flow then shipped to the third echelon to satisfy the local and international demands $j$, constraint (4.20).

$$
\sum_{p} \sum_{i \in N 1} w_{i j t}^{b} X_{i j w t}^{p}+\sum_{p} I_{j w t-1}^{p+}=\sum_{k \in N 3} X_{j k w t}^{b}+\sum_{p} I_{j w t}^{p+} \quad \forall b \in B, j \in N 2, k>j, w \in \Omega, t \in T .
$$

The by-products are stored in bulk plants before distribution to customers. Equation (4.21) represents the material balance at the bulk plant storage.

$$
\sum_{i \in N 2} X_{i j w t}^{b}+I_{j w t-1}^{b+}=\sum_{k \in N 3} X_{j k w t}^{b}+I_{j w t}^{b+} \quad \forall b \in B, j \in S, w \in \Omega, t \in T .
$$

\section{Plant and route capacities}

The input to any petroleum plants is limited by plant's capacity. Constraints (4.22)-(4.24) represent the capacity constraints of oil and gas storages, plants belong to the first and the second echelons of the oil and gas supply chain, respectively.

$$
\begin{array}{ccrl}
\sum_{r} Y_{i t}^{r}+\sum_{r} I_{i w t-1}^{r+} \leq C a_{i t} & \forall i \in S, w \in \Omega, t \in T \\
\sum_{r} \sum_{i \in S} X_{i j \omega t}^{r}+\sum_{r} I_{j w t-1}^{r+} \leq C a_{j t} & \forall j \in N 1, w \in \Omega, t \in T \\
\sum_{i \in N 1} \sum_{p} X_{i j w t}^{p}+\sum_{p} I_{j t-1}^{p+} \leq C a_{j t} & \forall j \in N 2, w \in \Omega, t \in T .
\end{array}
$$

The flow through in each arc is less than or equal route capacity; constraints (4.25)-(4.27).

$$
\begin{array}{ll}
X_{i j w t}^{r} \leq C r_{i j} & \forall i \in S, j \in N 1, p \in P, w \in \Omega, t \in T \\
X_{i j w t}^{p} \leq C r_{i j} & \forall i, j \in\{N 1, N 2, N 3\}, p \in P, w \in \Omega, t \in T \\
X_{i j w t}^{b} \leq C r_{i j} & \forall i, j \in\{N 1, N 2, N 3\}, b \in B, w \in \Omega, t \in T .
\end{array}
$$




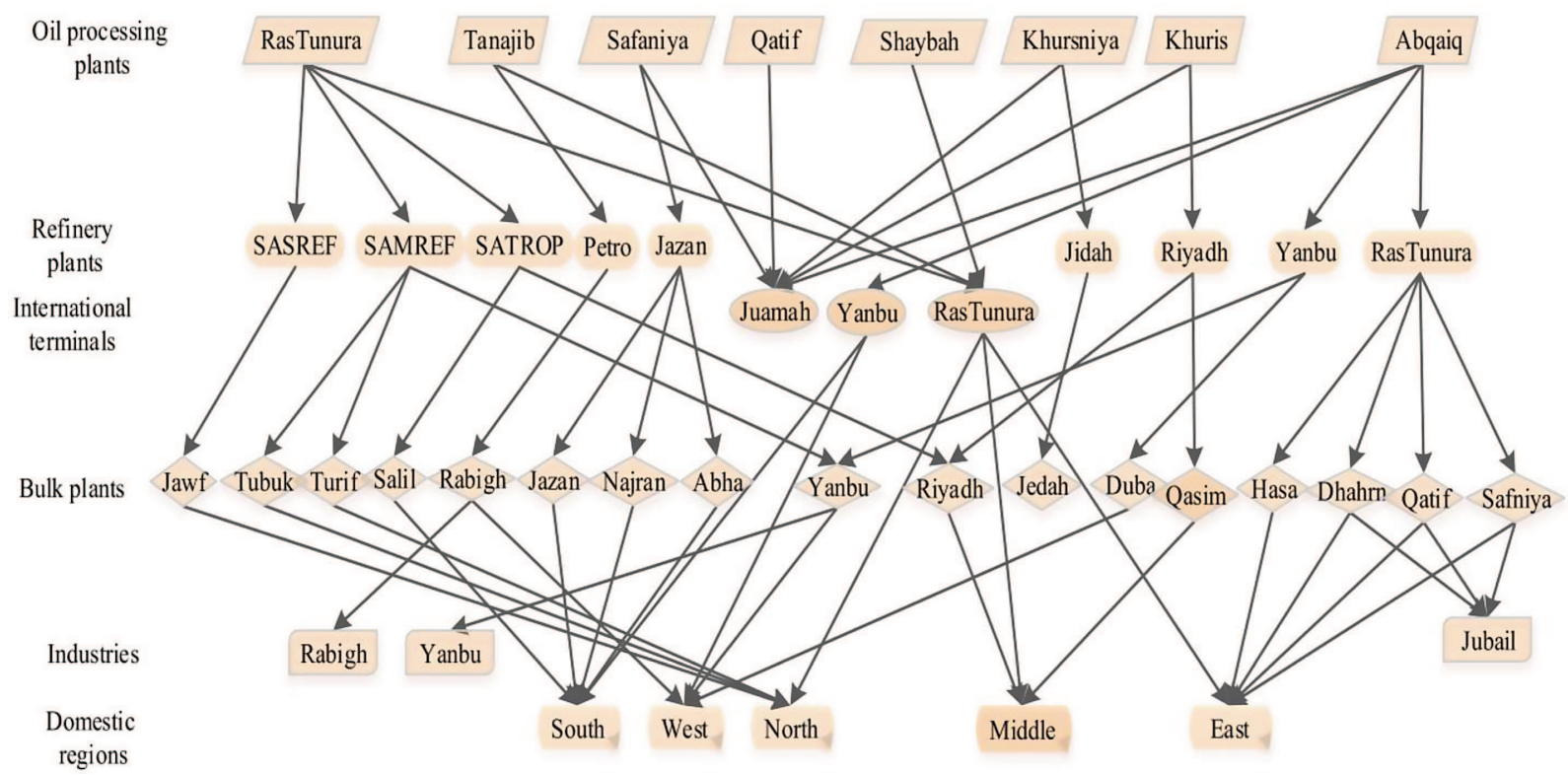

Figure 2. Saudi Arabia oil network [20].

\section{Demand and OPEC quota}

Constraints (4.28) and (4.29) represent demand for petroleum products at each demand node during time period $t$ under scenario $\omega$.

$$
\begin{array}{ll}
\sum_{i \in N 1} X_{i j w t}^{p}+\sum_{i \in N 4} X_{i j w t}^{p}-x_{j w t}^{p+}+x_{j w t}^{p-}=D_{j w t}^{p} & \forall j \in N 3, p \in P, w \in \Omega, t \in T \\
\sum_{i \in N 2} X_{i j w t}^{b}+\sum_{i \in N 4} X_{i j w t}^{b}-x_{j w t}^{b+}+x_{j w t}^{b-}=D_{j w t}^{b} & \forall j \in N 3, b \in B, w \in \Omega, t \in T .
\end{array}
$$

For each scenario $\omega$, exportation volumes from each crude oil type should not exceed the quota specified by OPEC to each member in the OPEC Organization, constraint (4.30).

$$
\sum_{i \in N 1} \sum_{j \in N 3} \sum_{p \in P} X_{i j w t}^{p} \leq \mathrm{OPEC}_{t} \quad \forall w \in \Omega, t \in T .
$$

\section{CASE Study}

The proposed mathematical model has been validated using the Saudi Arabia oil and gas supply chain. The oil and gas network under study is represented graphically in two separated figures for easy representation. Figures 2 and 3 illustrate the Saudi Arabian oil and natural gas networks, respectively. The network is a representation of the figures available in Murray [36]. The flow along the whole downstream segment is as follows: The sour oil produced at oil fields is processed at oil processing plants (i.e., Abqaiq, Shaybah, Khurais, Qatif, Khuraniyah, Safaniya, Tanajib, and RasTunura) to remove sulfur. After sweetening, sour oil is called crude oil. Saudi Arabia produces four types of crude oil (i.e., Arabian light, Arabian extra light, Arabian medium, and Arabian heavy). Then, crude oil is distributed to the local refinery plants (i.e., RasTunura, Yanbu, Riyadh, Jiddah, PetroRabigh, SAMREF, SASREF, and SATORP, and Jazan) and international markets (i.e., 


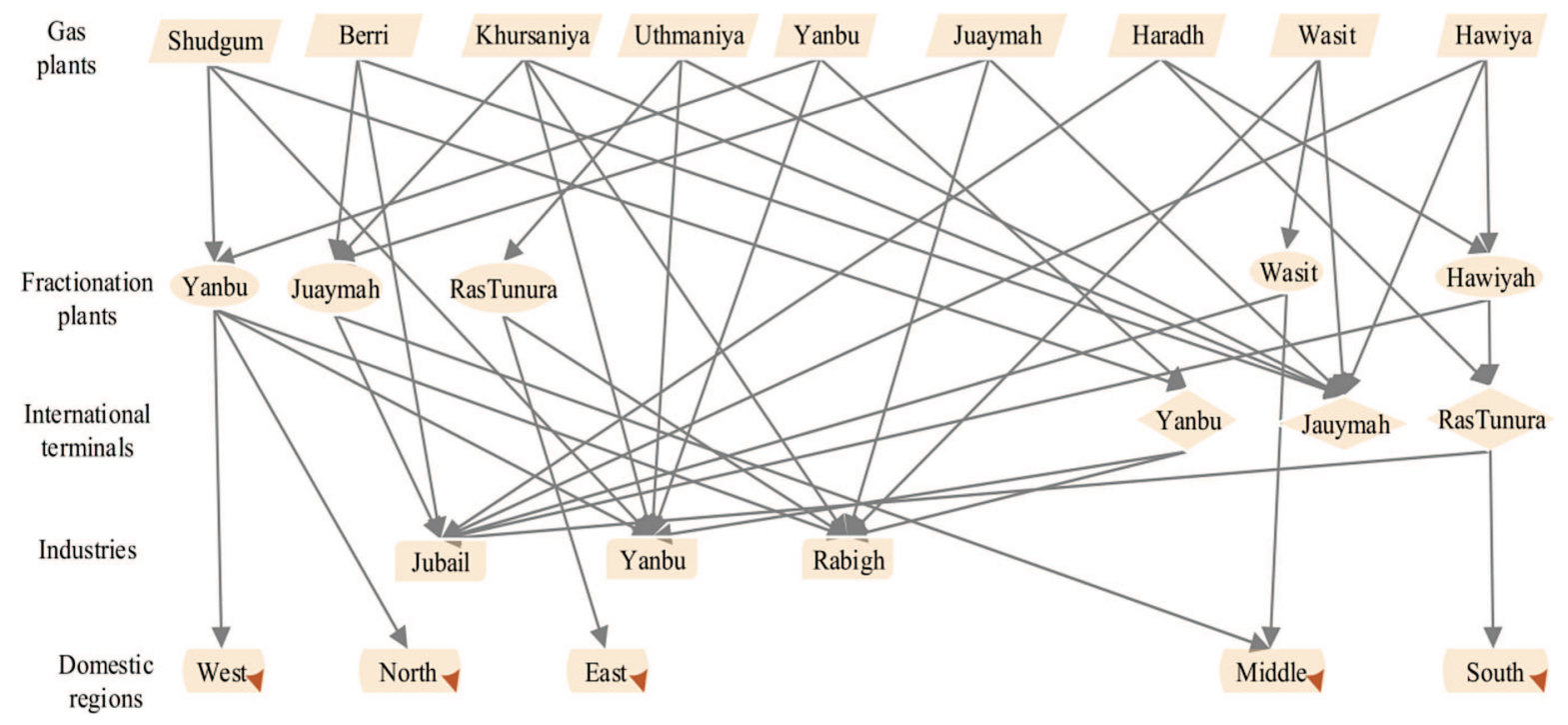

Figure 3. Saudi Arabia Natural gas network [20].

RasTunura, Jauymah, and Yanbu). The crude oil is processed into its by-products at the refinery plants. The oil by products are naphtha, gasoline, diesel, kerosene, fuel oil, propane, butane, and asphalt. These products are shipped to the bulk plants and then distributed to local customers of five regions (i.e., East, West, Middle, and South regions) and three industrial cities (i.e., Yanbu, Jubail, and Rabigh). The shortages of some oil products such as gasoline and diesel are imported from international markets. The oil by-products such as naphtha and fuel oil are exported to international markets.

The associated natural gas produced at GOSPs and the non-associated natural gas produced from pure gas fields are processed at the gas plants (i.e., Uthmaniyah, Berri, Shedgum, Khursaniyah, Yanbu, Haradh, Hawiyah, Juaymah, and Wasit) into natural gas liquid (NGL), methane and hydrogen sulfide. The methane is consumed locally to satisfy the industrial demand while the hydrogen sulfide is exported to the international markets. Part of the NGL is exported and some of it is sent to the fractionator plants (Juaymah, RasTunura, Yanbu, Wasit, and Hawiyah) for further processing into gas products such as ethane, butane, propane, and natural gasoline. The ethane volumes are consumed by industry. The other gas products are sent to the local and international customers. The shortages in meeting ethane demand are imported from international market.

The data needed to run the model are collected from different sources. The crude oil and gas compositions were collected from Al-Saleh et al. [4] and Duffuaa et al. [16]. The rest of data set including demands, prices, OPEC quota, capacities, and costs are collected from Ghaithan et al. [20], Attia et al. [5,6] and Ghaithan [19]. Two uncertain parameters have been considered: the demand and prices. The domestic demand is considered to be an uncertain parameter because the increase in the domestic demand of the petroleum products. This high variation is due to the rapid population growth of Kingdom of Saudi Arabia and due to high utilizing of crude oil in electricity generation, private and public sectors. The international price is selected to be consistent with the fluctuation in petroleum products prices due to the increase in production quantities of petroleum products over the world demand as noticed in the last years.

The uncertain parameters are represented by scenarios with associated probability of occurrence for each scenario. Three levels are assumed for each uncertain parameter; low, base, and high. The values of low, base, and high scenarios of uncertain parameters with their associated probabilities were assigned in accordance to Saudi Arabia case study and validated with experts from ARAMCO Company. The high-price and demand scenarios consider a $25 \%$ higher than the current case of petroleum products, while the low-price and demand 
TABLE 3. Realization and probabilities of uncertain parameters.

\begin{tabular}{lll}
\hline \hline $\begin{array}{c}\text { Uncertain } \\
\text { parameter }\end{array}$ & Realizations & Probability \\
\hline \multirow{4}{*}{ Demand } & Low & 0.25 \\
& Base & 0.50 \\
& High & 0.25 \\
\hline \multirow{2}{*}{ Price } & Low & 0.25 \\
& Base & 0.50 \\
& High & 0.25 \\
\hline
\end{tabular}

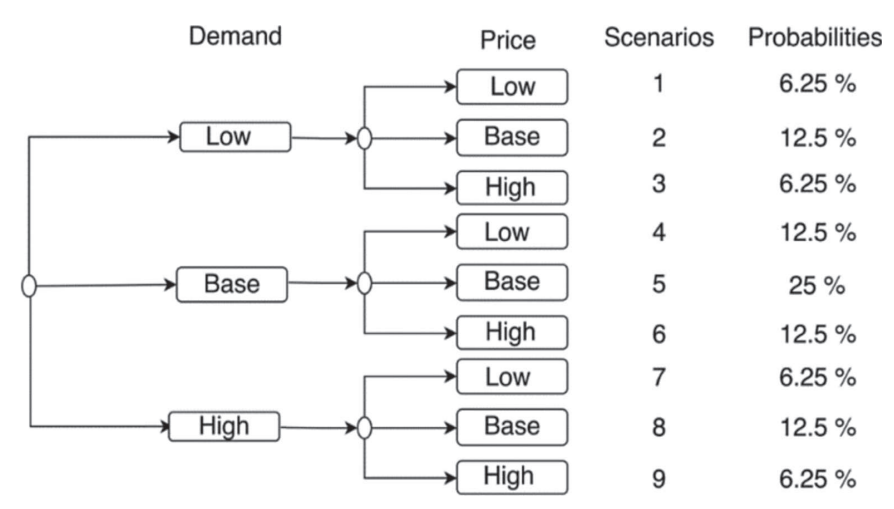

FiguRE 4. Scenario tree.

TABLE 4. Multi-objective stochastic model statistics.

\begin{tabular}{llll}
\hline \hline Blocks of equations & 96 & Single equations & 16897 \\
Blocks of variables & 75 & Single variables & 23846 \\
CPU time (s) & 3815 & Non-zero elements & 208552 \\
\hline
\end{tabular}

scenarios assumed to be $25 \%$ lower than the current case. The finite realization of scenarios construction were also used by other authors $[1,24,29,35,40]$.

Table 3 shows the probability of the three possible scenarios (High, Base, and Low) for each uncertain parameter. The joint probabilities of 9 scenarios are generated by multiplying the probabilities of uncertain parameters. Cooper [13] figured out that in oil and gas markets the demand is not highly insensitive to changes in price in the short run. Therefore, in this study demand and price are assumed to be independent as shown in scenario tree; Figure 4.

\section{Computational Results and Discussion}

The improved augmented $\varepsilon$-constraint algorithm is adopted in GAMS software and is used to solve the proposed model using the CPLEX 13.3 commercial solver [33]. A PC type Intel (R) Core (TM) i7-6600U CPU processor with $2.60 \mathrm{GHz}$ and $8 \mathrm{~GB}$ RAM was used for all computations in this paper. The planning horizon is three (3) months with a one-month planning period which represents the length of time period over which Saudi Arabia sign the contracts. The model statistics are summarized in Table 4. The mean computational time for this problem for 100 grid generated Pareto-optimal solutions is $64 \mathrm{~min}$. 
TABLE 5. The intervals of each objective function.

\begin{tabular}{llll}
\hline \hline & Total cost & Total revenue & Service level \\
\hline Min total cost & 6902.86 & 41446.91 & 0.821 \\
Max total revenue & 7661.66 & 41678.69 & 0.899 \\
Max service level & 7006.39 & 41503.86 & 0.950 \\
\hline
\end{tabular}

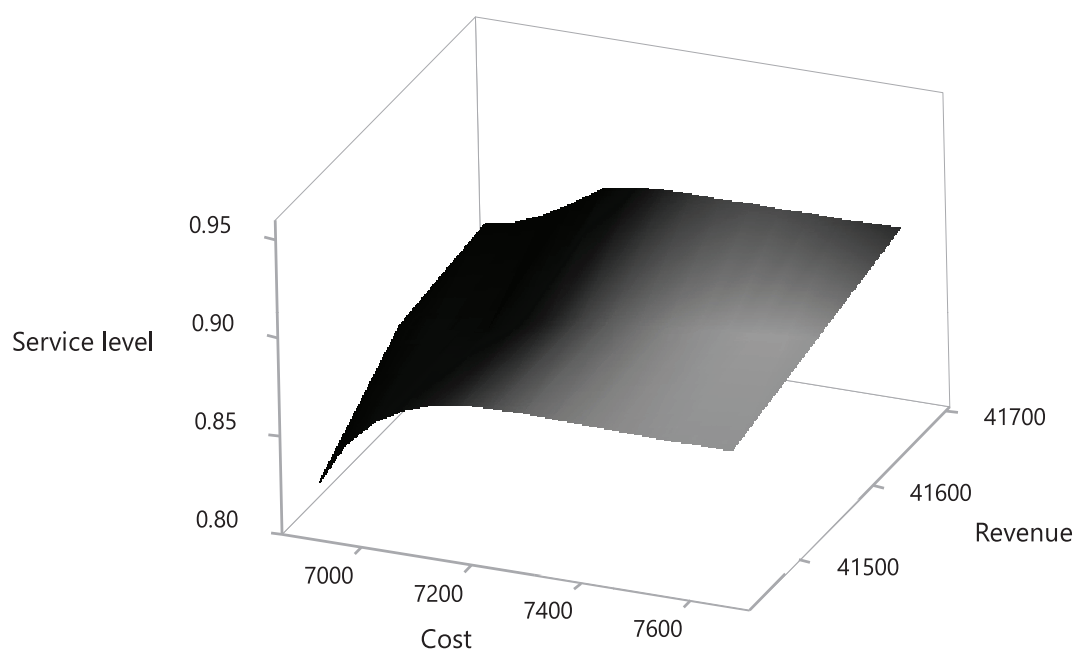

FiguRE 5. Pareto surface for the three objectives.

The interval of the three objective functions obtained by lexicographic optimization are summarized in Table 5. The values are obtained as follows; first, the model is solved as a single objective problem; minimization total cost which yields optimal total cost of $\$ 6902.86$ million per three months. Then, the model is optimized considering only maximization of total revenue after adding the obtained total cost value as a binding constraint; the optimal solution is $\$ 41678.69$ million per three months. Finally, the service level is optimized by adding the total cost and revenue values as binding constraints. To generate the values in the second and third rows, the same procedure is repeated considering different orders of the total revenue and service level.

After generating the intervals, the Pareto efficient solutions are then generated using a systematic search by dividing the ranges of revenue and service level equidistantly. The Pareto efficient solutions of the three objectives are plotted in Figure 5.

As service level increases, total revenue and cost increase. The increase in revenue is due to more sales which increases service level. The high sales lead to more production and then high production cost and transportation cost. Therefore, a least cost, high revenue and service level cannot be achieved simultaneously. Consequently, there is a trade-off between the selected objectives. Decision maker(s) can select his/her plan based on his/her preference using any multi-criteria decision making approaches.

For the purpose of comparison, one plan was selected from the set of Pareto solutions using a multi-criteria decision making approach called TOPSIS (Technique for Order Preference by Similarity to Ideal Solution) [11] assigning equal weight for each objective function. The ability of the stochastic programming approach to capture market uncertainties is evaluated using the EVPI and VSS. The EVPI measure is determined as the difference between stochastic solution and wait-and see solutions and it indicates how much is worth to know the future with full certainty. To study the impact of uncertainties of demand and price on oil and gas supply 
TABLE 6. EVPI (\$millions/3 months) when considering demand as uncertain parameter.

\begin{tabular}{llllllllll}
\hline \hline \multirow{2}{*}{$\begin{array}{l}\text { Pareto } \\
\text { set }\end{array}$} & \multicolumn{3}{c}{ Stochastic solution $\left(Z^{\mathrm{S}}\right)$} & \multicolumn{3}{c}{ Wait-and-see $\left(Z^{\mathrm{WS}}\right)$} & \multicolumn{3}{c}{ EVPI } \\
\cline { 2 - 10 } & $Z_{1}$ & $Z_{2}$ & $Z_{3}$ & $Z_{1}$ & $Z_{2}$ & $Z_{3}$ & $Z_{1}$ & $Z_{2}$ & $Z_{3}$ \\
\hline 1 & 6843.07 & 41459.14 & 0.823 & 6739.846 & 41469.18 & 0.859 & 103.221 & 10.042 & 0.036 \\
2 & 6847.59 & 41493.16 & 0.827 & 6744.525 & 41502.91 & 0.864 & 103.071 & 9.752 & 0.037 \\
3 & 6855.62 & 41525.11 & 0.857 & 6752.476 & 41534.57 & 0.890 & 103.144 & 9.452 & 0.033 \\
4 & 6867.69 & 41557.89 & 0.862 & 6769.730 & 41567.06 & 0.890 & 97.957 & 9.162 & 0.028 \\
5 & 6890.63 & 41589.44 & 0.862 & 6799.091 & 41598.30 & 0.890 & 91.539 & 8.862 & 0.028 \\
6 & 6937.77 & 41622.64 & 0.862 & 6856.127 & 41631.21 & 0.890 & 81.648 & 8.572 & 0.028 \\
7 & 7035.24 & 41652.21 & 0.883 & 7012.166 & 41660.49 & 0.890 & 23.069 & 8.281 & 0.007 \\
8 & 7675.84 & 41684.45 & 0.901 & 7616.422 & 41692.44 & 0.902 & 59.422 & 7.991 & 0.001 \\
9 & 6843.64 & 41467.08 & 0.841 & 6740.242 & 41471.62 & 0.873 & 103.400 & 4.541 & 0.032 \\
10 & 6845.14 & 41474.39 & 0.868 & 6741.432 & 41480.73 & 0.890 & 103.704 & 6.331 & 0.022 \\
11 & 6846.93 & 41474.12 & 0.860 & 6742.404 & 41483.97 & 0.901 & 104.521 & 9.852 & 0.041 \\
12 & 6850.80 & 41488.13 & 0.901 & 6744.257 & 41491.12 & 0.915 & 106.543 & 2.991 & 0.014 \\
13 & 6861.35 & 41500.13 & 0.878 & 6748.577 & 41506.30 & 0.929 & 112.776 & 6.171 & 0.051 \\
14 & 6892.12 & 41517.33 & 0.901 & 6758.961 & 41528.83 & 0.942 & 133.157 & 11.502 & 0.041 \\
15 & 6941.09 & 41533.67 & 0.897 & 6783.413 & 41539.08 & 0.956 & 157.676 & 5.411 & 0.059 \\
\hline
\end{tabular}

chain performance, the EVPI is calculated for each stochastic parameter separately. Table 6 lists the EVPI values when considering demand as uncertain parameter and price is fixed at the expected value. Table 7 shows the EVPI values when considering price as uncertain parameter and demand is fixed at the expected value.

As described in Section 4, the EVPI values in Tables 6 and 7 are obtained as follows: first the stochastic problem is solved for each scenario separately. Given the optimal solution and the probabilities of each scenario, the weighted averages is then calculated for all the solutions which represents the wait-and-see solution $\left(Z^{\mathrm{WS}}\right)$. Then the EVPI is calculated as the difference between the wait and see solutions $\left(Z^{\mathrm{WS}}\right)$ and the stochastic solutions $\left(Z^{\mathrm{S}}\right)$.

It can be concluded from Tables 6 and 7 that, the EVPI values when considering demand as uncertain parameter are higher than when considering price as uncertain parameter. This indicates that uncertainty in demand has higher impact on the generated plans. Consequently, it is crucial to accurately forecast the future market demand of petroleum products. Also these results should convince the oil decision makers to spend more on improving their knowledge of the stochastic parameters.

To measure the benefits of using stochastic programming approach over deterministic approach, the VSS is calculated; as the absolute difference between the EEV solutions and the SS solutions; Table 8. The VSS can be interpreted as the amount that the decision maker(s) would give up to use the stochastic solution. It is investigated that the VSS for total cost is higher than the VSS for total revenue and service level. The percentages of the VSS range $1.8 \%-12.6 \%, 0.0 \%-0.4 \%$, and $0.8 \%-6.2 \%$ of the wait-and-see solution for total cost, total revenue, and service level, respectively, which can be interpreted as a measure of the savings due to the consideration of uncertainty. The higher the VSS values, the better the stochastic programming approach to tackle the market uncertainties.

The VSS is determined as the difference between the stochastic solution $\left(Z^{\mathrm{S}}\right)$ and the expected value solution $\left(Z^{\mathrm{EV}}\right)$. The $Z^{\mathrm{EV}}$ is determined as follows: first the problem is solved as deterministic problem considering expected values of uncertain parameters. The obtained solutions are considered as first stage decisions for the stochastic problem. Then, the stochastic model is solved and the obtained objective function is the expected value solution $\left(Z^{\mathrm{EV}}\right)$.

In real-world, the price and demand parameters are dependent and correlated. The two parameters are negatively related; as price increases, demand decreases. Therefore, this relation can be analyzed by assigning high probabilities to the scenarios of (low demand-high price and high demand-low price). In scenario I, high 
TABLE 7. EVPI (\$millions/3 months) when considering price as uncertain parameter.

\begin{tabular}{llllllllll}
\hline \hline \multirow{2}{*}{$\begin{array}{l}\text { Pareto } \\
\text { set }\end{array}$} & \multicolumn{2}{c}{ Stochastic solution $\left(Z^{\mathrm{S}}\right)$} & \multicolumn{3}{c}{ Wait-and-see $\left(Z^{\mathrm{WS}}\right)$} & \multicolumn{3}{c}{ EVPI } \\
\cline { 2 - 10 }$Z_{1}$ & $Z_{2}$ & $Z_{3}$ & $Z_{1}$ & $Z_{2}$ & $Z_{3}$ & $Z_{1}$ & $Z_{2}$ & $Z_{3}$ \\
\hline 1 & 6527.61 & 41521.03 & 0.814 & 6527.61 & 41521.03 & 0.825 & 0.000 & 0.000 & 0.011 \\
2 & 6532.43 & 41551.43 & 0.818 & 6532.43 & 41551.45 & 0.835 & 0.000 & 0.020 & 0.018 \\
3 & 6539.56 & 41579.76 & 0.848 & 6539.55 & 41579.79 & 0.862 & 0.010 & 0.030 & 0.014 \\
4 & 6554.78 & 41608.92 & 0.853 & 6553.26 & 41608.97 & 0.869 & 1.560 & 0.050 & 0.016 \\
5 & 6576.56 & 41636.84 & 0.853 & 6574.57 & 41636.91 & 0.878 & 1.990 & 0.070 & 0.026 \\
6 & 6620.11 & 41666.41 & 0.853 & 6618.27 & 41666.49 & 0.878 & 1.840 & 0.090 & 0.026 \\
7 & 6750.10 & 41692.37 & 0.873 & 6742.84 & 41692.47 & 0.880 & 7.261 & 0.100 & 0.007 \\
8 & 7470.89 & 41720.99 & 0.891 & 7470.34 & 41721.09 & 0.902 & 0.550 & 0.110 & 0.011 \\
9 & 6529.03 & 41527.46 & 0.832 & 6528.96 & 41527.49 & 0.862 & 0.070 & 0.040 & 0.031 \\
10 & 6532.78 & 41547.89 & 0.859 & 6532.53 & 41548.79 & 0.872 & 0.250 & 0.890 & 0.013 \\
11 & 6541.85 & 41565.09 & 0.851 & 6540.99 & 41567.21 & 0.882 & 0.860 & 2.120 & 0.031 \\
12 & 6560.09 & 41588.36 & 0.891 & 6557.58 & 41590.56 & 0.904 & 2.510 & 2.200 & 0.013 \\
13 & 6587.71 & 41604.34 & 0.869 & 6584.22 & 41604.45 & 0.918 & 3.491 & 0.140 & 0.049 \\
14 & 6625.73 & 41598.56 & 0.891 & 6619.59 & 41599.64 & 0.931 & 6.131 & 1.080 & 0.039 \\
15 & 6679.29 & 41566.15 & 0.887 & 6668.32 & 41575.16 & 0.944 & 10.972 & 9.001 & 0.057 \\
\hline
\end{tabular}

TABLE 8. Value of the Stochastic Solutions (VSS).

\begin{tabular}{|c|c|c|c|c|c|c|c|c|c|c|c|c|}
\hline \multirow[t]{2}{*}{$\begin{array}{l}\text { Pareto } \\
\text { set }\end{array}$} & \multicolumn{3}{|c|}{$\begin{array}{c}\text { Stochastic solution } \\
\left(Z^{\mathrm{S}}\right)\end{array}$} & \multicolumn{3}{|c|}{$\begin{array}{c}\text { Expected value solution } \\
\left(Z^{\mathrm{EV}}\right)\end{array}$} & \multicolumn{3}{|c|}{$\begin{array}{c}\text { Value of Stochastic } \\
\text { Solution (VSS) }\end{array}$} & \multicolumn{3}{|c|}{$\begin{array}{l}\text { Improvement } \\
\left(\% \text { of } Z^{\mathrm{WS}}\right)\end{array}$} \\
\hline & $Z_{1}$ & $Z_{2}$ & $Z_{3}$ & $Z_{1}$ & $Z_{2}$ & $Z_{3}$ & $Z_{1}$ & $Z_{2}$ & $Z_{3}$ & $Z_{1}$ & $Z_{2}$ & $Z_{3}$ \\
\hline 1 & 6902.85 & 41551.71 & 0.857 & 7717.14 & 41446.91 & 0.821 & 814.29 & 104.8 & 0.036 & 12.0 & 0.3 & 4.4 \\
\hline 2 & 6904.25 & 41568.42 & 0.862 & 7718.11 & 41480.02 & 0.8 & 849.52 & 88.4 & 0.062 & 12.5 & 0.2 & 7.6 \\
\hline 3 & 6911.6 & 41585.13 & 0.888 & 7721.34 & 41513.13 & 0.855 & 844.02 & 72 & 0.033 & 12.5 & 0.2 & 3.9 \\
\hline 4 & 6922.23 & 41601.84 & 0.888 & 7725.52 & 41546.24 & 0.86 & 836.74 & 55.6 & 0.028 & 12.3 & 0.1 & 3.3 \\
\hline 5 & 6942.91 & 41618.55 & & 7729.69 & 41579.35 & & & 39.2 & & 12.0 & 0.1 & 3.3 \\
\hline 6 & 6981.69 & 41635.26 & 0.888 & 7736.89 & 41612.46 & 0.862 & 780.1 & 22.8 & 0.026 & 11.4 & 0.1 & 3.1 \\
\hline 7 & 7078.09 & 41651.97 & 0.888 & 7752.19 & 41645.58 & 0.881 & 681.12 & 6.39 & 0.007 & 9.7 & 0.0 & 0.8 \\
\hline 8 & 7661.66 & 41678.69 & 0.899 & 7801.47 & 41668.68 & 0.859 & 137.67 & 10.01 & 0.04 & 1.8 & 0.0 & 4.5 \\
\hline 9 & 6903.56 & 41559.39 & 0.871 & 7717.72 & 41455.78 & 0.839 & 852.43 & 103.61 & 0.032 & 12.6 & 0.3 & 3.8 \\
\hline 10 & 7661.66 & 41643.49 & 0.889 & 7718.52 & & & 852.09 & 64.8 & 0.01 & 12.6 & 0.2 & 1.2 \\
\hline 11 & 6904.86 & 41566.66 & 0.899 & 7719.83 & 41459.97 & 0.858 & 851.31 & 106.69 & 0.041 & 12.6 & 0.3 & 4.7 \\
\hline 12 & 7661.66 & 41678.71 & 0.913 & 7724.05 & 41615.67 & 0.899 & 851.52 & 63.04 & 0.014 & 12.6 & 0.2 & 1.6 \\
\hline 13 & 6907.48 & 41590.95 & 0.927 & 7736.16 & 41461.79 & 0.876 & 852.01 & 129.16 & 0.051 & 12.5 & 0.3 & 5.6 \\
\hline 14 & 7661.66 & 41678.68 & 0.94 & 7759.61 & 41607.69 & 0.899 & 847.57 & 70.99 & 0.041 & 12.4 & 0.2 & 4.4 \\
\hline 15 & 6912.61 & 41615.02 & 0.954 & 7792.35 & 41466.35 & 0.895 & 840.07 & 148.67 & 0.059 & 12.2 & 0.4 & 6.2 \\
\hline
\end{tabular}

probability (0.5) is assigned to scenario of (low demand-high price) and a probability of 0.5 is assigned to scenario II (high demand-low price).

One plan has been selected for each scenario (summarized in Tab. 9) using TOPSIS [11] with assigning equal weight for each objective function. It is noted that solution of scenario I is more profitable because high probability is assigned to scenarios of high prices. In addition, this plan shows more imports from international market than scenario II, because the probability of low demand is high and then no need to operate or fully utilize local resources. On the other hand, plan of scenario II leads to higher oil processing and refining and also higher gas fractioning because in this case, high probability is assigned for scenarios of high demands. Scenario 
TABLE 9. Preferred plan for scenarios I and II.

\begin{tabular}{llllllll}
\hline \hline Scenario & $\begin{array}{l}\text { Total } \\
\text { cost } \\
(\$ 10 \mathrm{E} 6)\end{array}$ & $\begin{array}{l}\text { Revenue } \\
(\$ 10 \mathrm{E} 6)\end{array}$ & $\begin{array}{l}\text { Service } \\
\text { level }\end{array}$ & $\begin{array}{l}\text { Oil } \\
\text { production } \\
(\mathrm{MBL} / \text { day })\end{array}$ & $\begin{array}{l}\text { Oil } \\
\text { imports } \\
(\mathrm{MBL} / \text { day })\end{array}$ & $\begin{array}{l}\text { Gas } \\
\text { production } \\
(\text { Mscft/day) }\end{array}$ & $\begin{array}{l}\text { Gas } \\
\text { imports } \\
\text { (Mscft/day) }\end{array}$ \\
\hline I & 6852 & 43823 & 0.924 & 9.87 & 0.351 & 12382 & 276 \\
II & 7652 & 39671 & 0.898 & 10.13 & 0.326 & 12216 & 253 \\
\hline
\end{tabular}

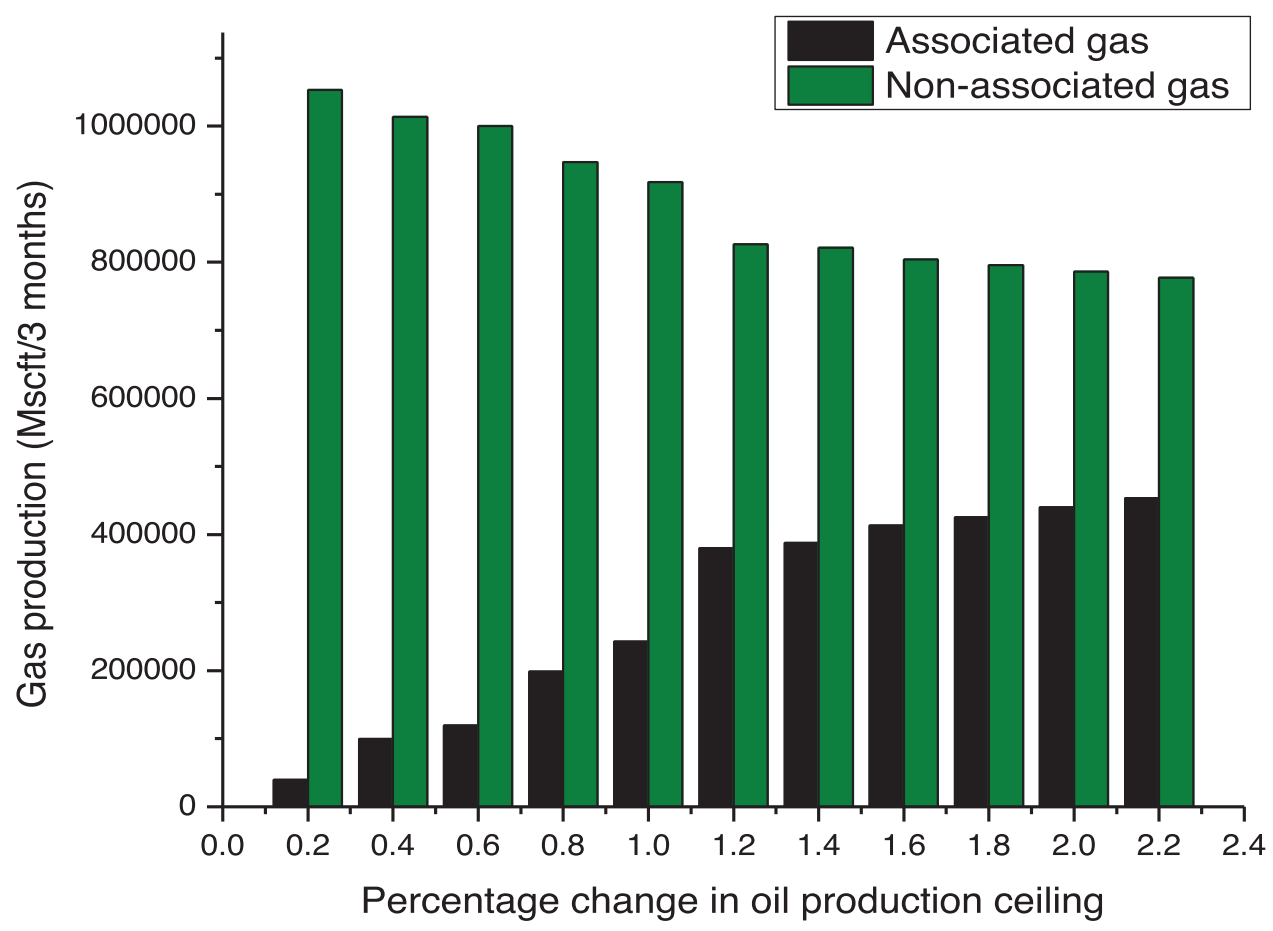

FiguRE 6. Associated and non-associated gas productions versus crude oil production ceiling.

I shows higher service level than scenario II since high probability is assigned to low demand and high prices which means that most of demand is satisfied.

Nature has made the crude oil in Saudi Arabia in most of its oil fields has associated gas. Furthermore, propane and butane are produced from fractionation plants and refinery plants. Therefore, it is necessary to integrate the oil and gas networks. To highlight the importance of interaction between oil and gas networks, a sensitivity analysis is conducted to study the impact of changing oil production ceiling (represented by OPEC quota) on the availability of gas to Saudi Arabia petrochemical industries.

To investigate the effect of changing OPEC quota on the associated and non-associated gas processing, we evaluated the results based on 11 levels of the OPEC quota, given the current OPEC quota allocated for Saudi Arabia is 9.7 million barrel per day. The obtained associated and non-associated gas productions versus crude oil production ceiling variations are plotted in Figure 6.

The results indicate high dependency between oil and natural gas productions. As oil production ceiling increases, the amount of associated gas production increases and the non-associated gas decreases. This is expected since the associated gas is separated from crude oil. In addition, the increase in associated gas 


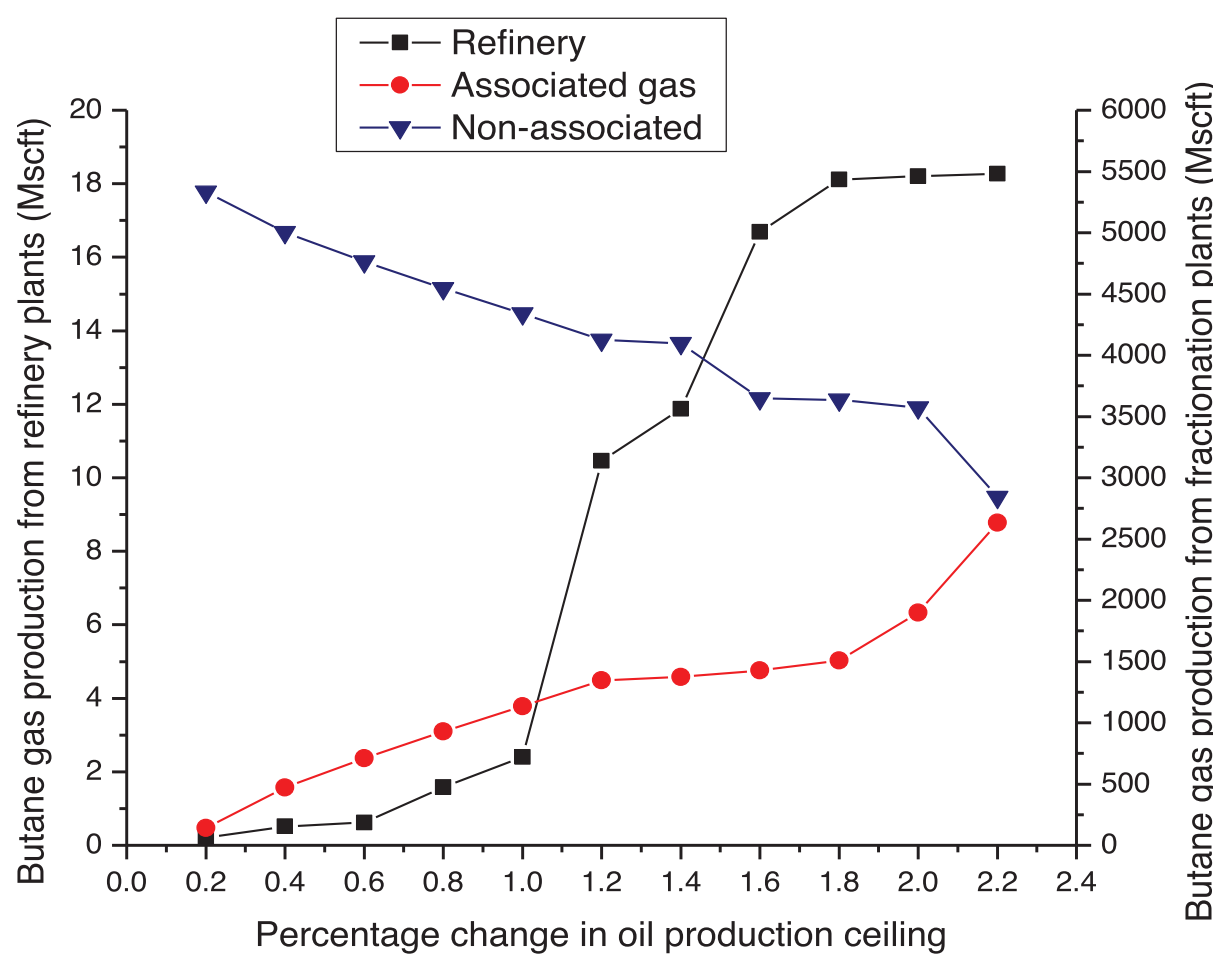

FiguRE 7. Butane gas satisfaction from fractionation and refinery plants for scenario 5 (Base demand-base price).

production leads to a reduction in non-associated gas production since the two gas types compete to satisfy the demand of lower gas entities. This figure demonstrates that Saudi Arabia can satisfy gas demands for its petrochemical industry from non-associated gas when oil production ceiling decreases.

The impact of oil production ceiling variations on butane gas production from refinery plants and fractionation plants are shown in Figure 7. As oil production ceiling increases, the amount of butane gas obtained from refinery plants and associated gas increases. On the other hand, butane obtained from non-associated gas decreases with increasing oil production. This variation confirms the high dependency between refinery plants and fractionation plants since these two resources produce butane gas. With increasing Saudi Arabia OPEC share, demand for butane gas would be satisfied from refinery plants and associated gas. Decreasing Saudi Arabia OPEC share lower than 2 million barrels per day, demand for butane gas will be satisfied from non-associated gas processes at fractionation plants.

\section{Conclusion}

In this study, a multi-objective stochastic model has been developed for tactical planning of oil and gas supply chain. The domestic demand and international price were considered to be stochastic parameters. Three conflicting criteria are considered including minimization of total cost, maximization of total revenue, and maximization of service level. The model is formulated based on two-stage stochastic approach representing the uncertain parameters as set of realizations with known probabilities. The applicability of the model is demonstrated using the case of Saudi Arabia oil and gas supply chain. The advantage of using stochastic modeling approach over deterministic approach has been proven using the EVPI and the VSS quality measures. The generated plans have considerably higher EVPI values when considering demand as stochastic compared to when considering price as uncertain parameter which indicates that demand has higher impact on the 
supply chain planning than price. Also, the generated plans have higher VSS for total cost which justify the importance of the stochastic approach over the deterministic programming approach. Future research should consider integrating oil and gas supply chain with other energy resources such as renewable energy, environmental aspects; emissions, security, and sustainability along with economic aspects during modeling of oil and gas supply chain. In addition, different modeling techniques could be utilized to model supply chain under uncertainty such as chance constraints programming and robust optimization. The accuracy of the results can be improved using machine learning techniques to predict price and demand. Besides, it is interesting to conduct sensitivity analysis to study different probabilities to different scenarios. Moreover, potential factors that affect the probability of occurrence of scenarios could be identified by conducting comprehensive literature reviews and experts' interviews. Then, the probability of scenarios occurrence would be assessed using Markov decision process (MDP) in order to simulate the behavior of uncertain parameters.

Acknowledgements. The authors thank King Fahd University of Petroleum and Minerals for the support and facilities that made this research possible.

\section{REFERENCES}

[1] W.B. Al-Othman, H.M. Lababidi, I.M. Alatiqi and K. Al-Shayji, Supply chain optimization of petroleum organization under uncertainty in market demands and prices. Eur. J. Oper. Res. 189 (2008) 822-840.

[2] K. Al-Qahtani and A. Elkamel, Multisite refinery and petrochemical network design: optimal integration and coordination. Ind. Eng. Chem. Res. 48 (2008) 814-826.

[3] K. Al-Qahtani and A. Elkamel, Robust planning of multisite refinery networks: optimization under uncertainty. Comput. Chem. Eng. 34 (2010) 985-995.

[4] M.A. Al-Saleh, S.O. Duffuaa, M.A. Al-Marhoun and J.A. Al-Zayer, Impact of crude oil production on the petrochemical industry in Saudi Arabia. Energy 16 (1991) 1089-1099.

[5] A.M. Attia, A.M. Ghaithan and S.O. Duffuaa, A multi-objective optimization model for tactical planning of upstream oil \& gas supply chains. Comput. Chem. Eng. 128 (2019) 216-227.

[6] A.M. Attia, A.M. Ghaithan and S.O. Duffuaa, Data on upstream segment of a hydrocarbon supply chain in Saudi Arabia. Data Brief 27 (2019) 104804.

[7] A. Azadeh, Z. Raoofi and M. Zarrin, A multi-objective fuzzy linear programming model for optimization of natural gas supply chain through a greenhouse gas reduction approach. J. Nat. Gas. Sci. Eng. 26 (2015) 702-710.

[8] A. Azadeh, F. Shafiee, R. Yazdanparast, J. Heydari and A. Keshvarparast, Optimum integrated design of crude oil supply chain by a unique mixed integer nonlinear programming model. Ind. Eng. Chem. Res. 56 (2017) 5734-5746.

[9] J.R. Birge and F. Louveaux, Introduction to Stochastic Programming. Springer Science \& Business Media (2011).

[10] M.C. Carneiro, G.P. Ribas and S. Hamacher, Risk management in the oil supply chain: a CVaR approach. Ind. Eng. Chem. Res. 49 (2010) 3286-3294.

[11] R.T. Clemen and T. Reilly, Making Hard Decisions with Decision Tools Suite Update Edition. Cengage Learning, Pacific Grove, CA (2004).

[12] A.J. Conejo, M. Carrión and J.M. Morales, Decision Making Under Uncertainty in Electricity Markets. Springer (2010).

[13] J.C. Cooper, Price elasticity of demand for crude oil: estimates for 23 countries. OPEC Rev. 27 (2003) 1-8.

[14] G.B. Dantzig, Linear programming under uncertainty. In: Stochastic Programming. Springer (2010) 1-11.

[15] M.A.H. Dempster, N.H. Pedron and E.A. Medova, Planning logistics operations in the oil industry. J. Oper. Res. Soc. 51 (2000) 1271-1288.

[16] S.O. Duffuaa, J.A. Al-Zayer, M.A. Al-Marhoun and M.A. Al-Saleh, A linear programming model to evaluate gas availability for vital industries in Saudi Arabia. J. Oper. Res. Soc. 43 (1992) 1035-1045.

[17] L.F. Escudero, F.J. Quintana and J. Salmerón, CORO, a modeling and an algorithmic framework for oil supply, transformation and distribution optimization under uncertainty. Eur. J. Oper. Res. 114 (1999) 638-656.

[18] L.J. Fernandes, S. Relvas and A.P. Barbosa-Póvoa, Downstream petroleum supply chain planning under uncertainty. In: Vol. 37 of Computer Aided Chemical Engineering (2015) 1889-1894.

[19] A.M. Ghaithan, An optimization model for operational planning and turnaround maintenance scheduling of oil and gas supply chain. Appl. Sci. 10 (2020) 7531.

[20] A.M. Ghaithan, A. Attia and S.O. Duffuaa, Multi-objective optimization model for a downstream oil and gas supply chain. Appl. Math. Model. 52 (2017) 689-708.

[21] M. Ghatee and S.M. Hashemi, Optimal network design and storage management in petroleum distribution network under uncertainty. Eng. Appl. Artif. Intell. 22 (2009) 796-807.

[22] E.T. Iakovou, An interactive multiobjective model for the strategic maritime transportation of petroleum products: risk analysis and routing. Saf. Sci. 39 (2001) 19-29.

[23] C.S. Khor, A. Elkamel and P.L. Douglas, Stochastic refinery planning with risk management. Pet. Sci. Technol. 26 (2008) 1726-1740. 
[24] H.M.S. Lababidi, M.A. El-Wakeel, I.M. Alatiqi and A.F. Al-Enzi, Optimizing the supply chain of petrochemical products under uncertain operational and economical conditions. jdt 1 (2003).

[25] H.M. Lababidi, M.A. Ahmed, I.M. Alatiqi and A.F. Al-Enzi, Optimizing the supply chain of a petrochemical company under uncertain operating and economic conditions. Ind. Eng. Chem. Res. 43 (2004) 63-73.

[26] A. Leiras, A. Elkamel and S. Hamacher, Strategic planning of integrated multirefinery networks: a robust optimization approach based on the degree of conservatism. Ind. Eng. Chem. Res. 49 (2010) 9970-9977.

[27] A. Leiras, G. Ribas, S. Hamacher and A. Elkamel, Literature review of oil refineries planning under uncertainty. Int. J. Oil Gas Coal Technol. 4 (2011) 156-173.

[28] W. Li, C.-W. Hui, P. Li and A.-X. Li, Refinery planning under uncertainty. Ind. Eng. Chem. Res. 43 (2004) $6742-6755$.

[29] Z. Li, Y. Zhang and G. Zhang, Two-stage stochastic programming for the refined oil secondary distribution with uncertain demand and limited inventory capacity. IEEE Access 8 (2020) 119487-119500.

[30] C. Lima, S. Relvas and A.P.F. Barbosa-Póvoa, Downstream oil supply chain management: a critical review and future directions. Comput. Chem. Eng. 92 (2016) 78-92.

[31] C. Lima, S. Relvas and A. Barbosa-Povoa, Stochastic programming approach for the optimal tactical planning of the downstream oil supply chain. Comput. Chem. Eng. 108 (2018) 314-336.

[32] H. Liqiang and W. Guoxin, Two-stage stochastic model for petroleum supply chain from the perspective of carbon emission. In: Vol. 117 of Proceedings of the International Conference on Logistics, Engineering, Management and Computer Science (2015) 926-930.

[33] C.U. Manual, Ibm ilog cplex optimization studio. Version 12 (1987) 1987-2018.

[34] G. Mavrotas and K. Florios, An improved version of the augmented $\varepsilon$-constraint method (AUGMECON2) for finding the exact pareto set in multi-objective integer programming problems. Appl. Math. Comput. 219 (2013) 9652-9669.

[35] S.A. MirHassani, An operational planning model for petroleum products logistics under uncertainty. Appl. Math. Comput. 196 (2008) 744-751.

[36] S. Murray, Energy to the World: The Story of Saudi ARAMCO, 1st edition. Vol. 2, Houston, Texas, USA (2011).

[37] S.M. Neiro and J.M. Pinto, Multiperiod optimization for production planning of petroleum refineries. Chem. Eng. Comm. 192 (2005) 62-88.

[38] F. Oliveira and S. Hamacher, Optimization of the petroleum product supply chain under uncertainty: a case study in northern brazil. Ind. Eng. Chem. Res. 51 (2012) 4279-4287.

[39] F. Oliveira, V. Gupta, S. Hamacher and I.E. Grossmann, A Lagrangean decomposition approach for oil supply chain investment planning under uncertainty with risk considerations. Comput. Chem. Eng. 50 (2013) 184-195.

[40] G.P. Ribas, S. Hamacher and A. Street, Optimization under uncertainty of the integrated oil supply chain using stochastic and robust programming. Int. Trans. Oper. Res. 17 (2010) 777-796.

[41] G. Ribas, A. Leiras and S. Hamacher, Tactical planning of the oil supply chain: optimization under uncertainty. Pre-An XLIIISBPO (2011).

[42] H. Sahebi, S. Nickel and J. Ashayeri, Strategic and tactical mathematical programming models within the crude oil supply chain context - A review. Comput. Chem. Eng. 68 (2014) 56-77.

[43] M. Stewart and K.E. Arnold, Surface Production Operations, Design of Oil Handling Systems and Facilities, 3rd edition. Vol. 1, Gulf Professional Publishing, Amsterdam, Boston, Houston, TX (2007).

[44] K. Tong, Y. Feng and G. Rong, Planning under demand and yield uncertainties in an oil supply chain. Ind. Eng. Chem. Res. 51 (2012) 814-834.

[45] J. Yang, H. Gu and G. Rong, Supply chain optimization for refinery with considerations of operation mode changeover and yield fluctuations. Ind. Eng. Chem. Res. 49 (2010) 276-287.

\section{Subscribe to Open (S2O)}

\section{A fair and sustainable open access model}

This journal is currently published in open access under a Subscribe-to-Open model (S2O). S2O is a transformative model that aims to move subscription journals to open access. Open access is the free, immediate, online availability of research articles combined with the rights to use these articles fully in the digital environment. We are thankful to our subscribers and sponsors for making it possible to publish this journal in open access, free of charge for authors.

\section{Please help to maintain this journal in open access!}

Check that your library subscribes to the journal, or make a personal donation to the $\mathrm{S} 2 \mathrm{O}$ programme, by contacting subscribers@edpsciences.org

More information, including a list of sponsors and a financial transparency report, available at: https://www. edpsciences.org/en/maths-s2o-programme 